\title{
A higher level of prostaglandin E2 in the urinary bladder in young boys and boys with lower urinary tract obstruction
}

\author{
Katsuya Aoki, Akihide Hirayama, Nobumichi Tanaka, Tatsuo Yoneda, Katsunori Yoshida, Kiyohide Fujimoto \\ and Yoshihiko HiRAO \\ Department of Urology, Nara Medical University, Nara, Japan
}

(Received 30 September 2009; and accepted 14 October 2009)

\begin{abstract}
We conducted two studies to examine the hypothesis that lower urinary tract obstruction induces excessive production of prostaglandin E2 (PGE2) in the bladder in young boys, with consequent overactive bladder (OAB) symptoms. The subjects were boys aged less than 15 years old who were scheduled to undergo surgery in our department from October 2006 to March 2008. In study $1(\mathrm{n}=25)$, the patients were divided into two groups based on the presence or absence of lower urinary tract obstruction. In study $2(\mathrm{n}=38)$, the patients were classified by age. The PGE2 level in the bladder was determined by washing with saline before the operation and urinary symptoms were evaluated using the Pediatric Lower Urinary Tract Scoring System. In study 1, the PGE2 level in the bladder of patients with lower urinary tract obstruction was higher than in those without obstruction $(49.1 \pm 37.4$ vs. $21.5 \pm 10.1 \mathrm{pg} / \mathrm{mL}, P=0.0475)$. In study 2 , the PGE2 level in the bladder was negatively correlated with age $(r=-0.379, P=0.0207)$. A higher level of PGE2 is found in boys with bladder outlet obstruction due to urethral stricture and in younger boys, and this elevated level of PGE2 may induce OAB symptoms.
\end{abstract}

Lower urinary tract obstruction (LUTO) in boys can induce daytime incontinence and pollakisuria (10). In adults, these symptoms are referred to as overactive bladder $(\mathrm{OAB})$ syndrome. Based on studies in adult human and in animal models, activation of capsaicin-sensitive fibers (C-fibers) is thought to be one etiology of OAB syndrome induced by LUTO. Several substances derived from the bladder have been associated with reactivation of $\mathrm{C}$-fibers, including prostaglandin E2 (PGE2). PGE2 has an important role in regulation of lower urinary tract function (2), and its overexpression in the bladder stimulates the micturition reflex through activation of $\mathrm{C}$-fibers in a rat model (9). Moreover, instillation of PGE2 into the bladder of adults induces detrusor overac-

Address correspondence to: Akihide Hirayama, M.D., Department of Urology, Nara Medical University, 840 Shijo-cho, Kashihara, Nara 634-8522, Japan

Tel: +81-744-22-3051, Fax: +81-744-22-9282

E-mail: hirayamn@naramed-u.ac.jp tivity and $\mathrm{OAB}$ symptoms (13).

The relationship of LUTO and excessive production of PGE2 in animal models and adult human has not been clarified in children, as far as we are aware. For many boys with LUTO, a voiding cystourethrogram or urethrocystoscopy under general anesthesia is required to diagnose the extent of LUTO. However, these examinations are invasive for young boys and do not always allow clarification of the degree of LUTO, which makes it difficult to determine whether an operation should be performed. Consequently, new methods of diagnosis of LUTO in boys are required. Also, the voiding detrusor pressure is reported to be higher in male infants than in older children or adults $(4,14,18)$, and excessive production of PGE2 in the urinary bladder in young boys may be induced by overdistention of the bladder wall, as well as by LUTO. To address these issues, we conducted two studies to examine the hypothesis that LUTO induces higher levels of PGE2 in the bladder in young boys, with conse- 
quent $\mathrm{OAB}$ symptoms such as daytime incontinence and pollakisuria.

\section{MATERIALS AND METHODS}

Patients. The objectives and methods of the study were approved by our institutional review board and were fully explained to the patients' parents, who then provided informed consent. The subjects were 47 children who underwent urologic surgery in our institution from October 2006 to March 2008 (Table 1). The exclusion criteria were chronic renal failure (serum $\mathrm{Cr}$ level $>1.0 \mathrm{mg} / \mathrm{dL}$ ), urinary tract infection with a white blood cell count $>5 /$ high power field in the urine, use of non-steroidal antiinflammatory drugs, spinal cord disease, neuropathy, hydronephrosis, and vesicoureteral reflux. In addition, we excluded the patents with samples of creatinine $(\mathrm{Cr})$ level $>$ the normal average $+0.5 \mathrm{SD}$ to minimize the influence of PGE2 derived from the kidney.

Definition of lower urinary tract obstruction. The bladder wall thickness was measured using transabdominal ultrasonography when the volume of urine in the bladder was more than half the estimated maximum bladder capacity (urine volume $>[$ age + 2) $\times 15 \mathrm{~mL}]$ ). A bladder wall thickness $>3 \mathrm{~mm}$ was taken to indicate possible lower urinary tract dysfunction (8). Patients $\geq 4$ years old with suspected LUTO subsequently underwent voiding cystourethrography and direct vision internal urethrotomy (DVIU) to establish a definite diagnosis.

Urine collection and measurement of urinary PGE2 and $\mathrm{Cr}$. Urine samples were collected before surgery under general anesthesia. The urine was drained through a catheter and then a volume of saline $25 \%$ that of the estimated maximum bladder capacity (saline volume $=[($ age +2$) \times 7.5 \mathrm{~mL}])$ was instilled into the urinary bladder and collected one minute later. The PGE2 concentration was estimated using a radioimmunoassay with an $\left[\mathrm{I}^{125}\right]$ PGE2 RIA Kit (PerkinElmer TM, Waltham, MA, USA).

Table 1 The underlying disease in patients enrolled in this study

\begin{tabular}{lc}
\hline & Children (n) \\
\hline Undescended testis, inguinal hernia, hydrocele & 28 \\
Hypospadias, concealed penis, phimosis & 10 \\
Urethral stricture & 9 \\
\hline
\end{tabular}

Study 1. The subjects in study 1 were 25 patients of age $\geq 4$ years old (range 4-12 years old) who were divided into groups with and without LUTO: the LUTO group and the control group (Fig. 1). In the control group, patients with a bladder wall thickness $>3 \mathrm{~mm}$ were excluded. Urinary PGE2 and $\mathrm{Cr}$ were determined as described above. Urinary symptoms were evaluated using the $\mathrm{OAB}$ section of the Pediatric Lower Urinary Tract Scoring System (P-LUTSS) (16). This questionnaire consists of 10 qualitative and quantitative questions regarding urinary incontinence, voiding habits, urgency, posturing, bowel habits, and stressful life events. Questions are scored from 0 to 3 , with higher scores indicating greater dysfunction. The $\mathrm{OAB}$ section of the questionnaire has 4 questions, and therefore the total score in this study ranged from 0 to 12 .

Study 2. The subjects were 38 patients (Fig. 1) without obvious LUTO based on the definition above. Urinary PGE2 and Cr were measured as described above.

Statistical analysis. A Mann-Whitney U test and post hoc tests were used for intergroup comparisons, with $P<0.05$ considered to be statistically significant. StatView v. 5.0 (SAS Institute, Cary, NC, USA) was used to conduct all analyses.

\section{RESULTS}

Study 1

The 25 patients were divided into groups with LUTO $(\mathrm{n}=9$, mean age $6.7 \pm 1.9$ years old) and without LUTO (control group, $\mathrm{n}=16$, mean age $7.1 \pm 2.7$ years old). Age did not differ significantly between the groups $(P=0.84)$. The PGE2 level in patients

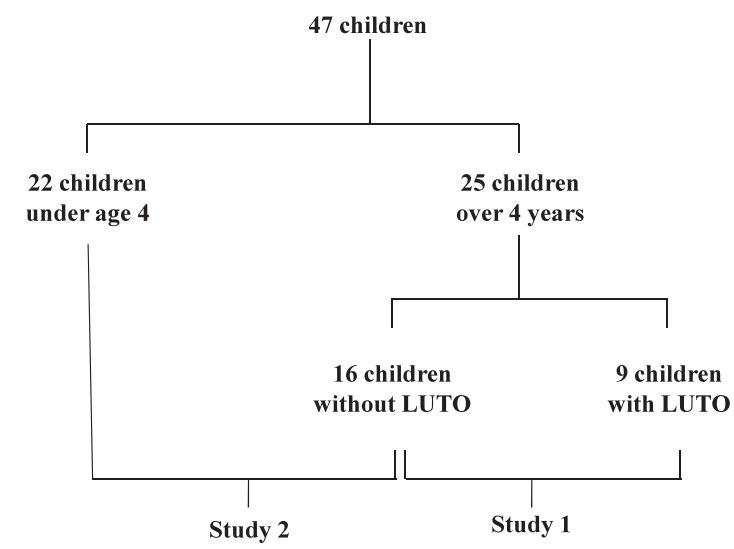

Fig. 1 Number and age of patients. 
with LUTO was significantly higher than in controls without LUTO $(49.1 \pm 37.4$ vs. $21.5 \pm 10.1 \mathrm{pg} / \mathrm{mL}$, $P=0.0475$, Fig. 2) and the bladder wall thickness was also higher in patients with LUTO $(4.0 \pm 0.5$, range $3.2-4.6 \mathrm{~mm})$ than in controls $(1.6 \pm 0.5$, range $1.0-2.9 \mathrm{~mm})$. The score for the OAB section of the P-LUTSS was significantly higher for patients with LUTO (mean 9.44, range 6-12 vs. mean 0.38 , range $0-3 ; P<0.001)$. Various degrees of urethral stricture were evident on voiding cystourethrography and DVIU in all 9 patients with LUTO. OAB symptoms resolved within 6 months in all patients after DVIU, and the mean score for the $\mathrm{OAB}$ section of the P-LUTSS showed a significant decrease to 0.33 (range 0-2) after DVIU $(P<0.001$, Fig. 3). We could obtain the samples in the 2 patients on postoperative 6 months. The PGE2 level in those patients decreased after surgery $(65 \rightarrow 19 \mathrm{pg} / \mathrm{mL}, 58 \rightarrow$ $21 \mathrm{pg} / \mathrm{mL})$.

\section{Study 2}

The PGE2 level in the urinary bladder in patients without LUTO $(\mathrm{n}=38)$ was negatively correlated with age ( $r=-0.379, P=0.0207$, Fig. 4$)$.

\section{DISCUSSION}

Prostanoids such as prostaglandin E2 (PGE2) are implicated as endogenous modulators of bladder function under various physiological and pathophysiological conditions (1). PG synthesis in the urothe-

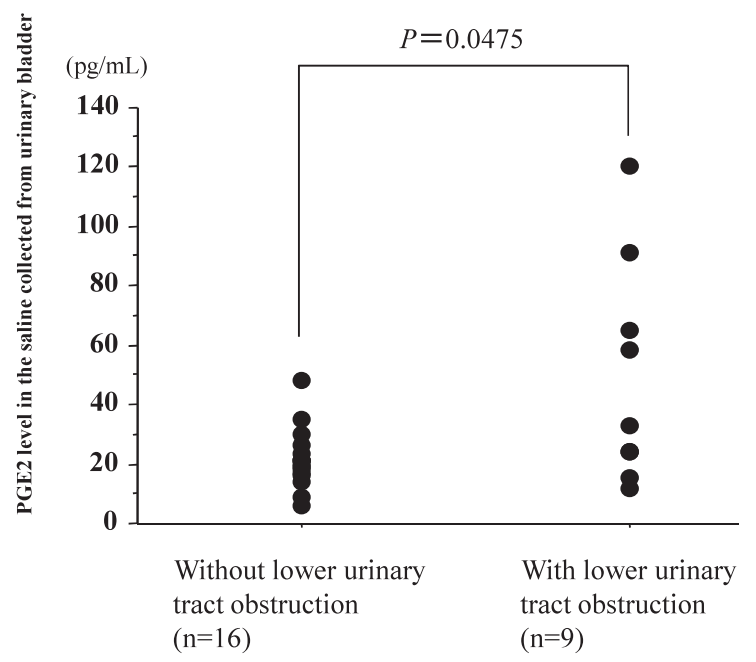

Fig. 2 Level of PGE2 in the urinary bladder in patients with or without lower urinary tract obstruction. The PGE2 level was higher in patients with lower urinary tract obstruction than in those without lower urinary tract obstruction $(49.1 \pm 37.4$ vs. $21.5 \pm 10.1 \mathrm{pg} / \mathrm{mL}, P=0.0475)$. lium of the urinary bladder of adult human is thought to be initiated by various physiological stimuli such as detrusor muscle stretching with bladder outlet obstruction. An increase in cyclooxygenase-2 expression and PGs in the bladder wall has an important role in the development of detrusor overactivity caused by bladder outlet obstruction (11, 12). The excitatory influences of PGE2 on the micturition reflux are attributable to stimulation of C-fiber afferent nerves via the EP1 receptor (19), but there have been no reports on PG synthesis in the urinary bladder of young boys.

PGE2 produced in the kidney should be considered when measuring the bladder level of PGE2 in urine. Urinary PGE2 is predominantly derived from the kidney $(3,15)$ and measurement of urinary PGE2 can be used to investigate kidney function (7, 17). In this study, we measured urinary PGE2 and $\mathrm{Cr}$ in saline that was instilled into the bladder for 1 minute after emptying of urine from the bladder, and we also excluded patients with a $\mathrm{Cr}$ level of more than the normal average $+0.5 \mathrm{SD}$ in the samples. Urinary $\mathrm{Cr}$ is excreted from the kidney only, and not from the bladder, and therefore a high value of $\mathrm{Cr}$ in a particular sample indicated that the sample contained a relatively high amount of urine, and thus may contain PGE2 from the kidney. Such samples were excluded from data analysis. By this means, we eliminated the influence of PGE2 from the kidney on measurement of PGE2 level from the urinary bladder.

In study 1, the PGE2 level in patients with LUTO was significantly higher than in those without LUTO. Since we excluded patients with diseases in-

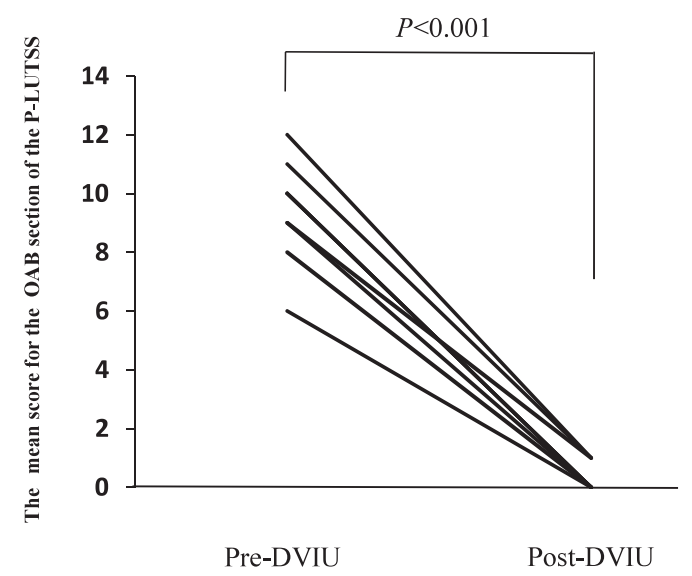

Fig. 3 The mean score for the OAB section of the P-LUTSS showed a significant decrease from 9.44 (range $6-12$ ) before DVIU to 0.33 (range $0-2$ ) after DVIU $(P<0.001)$. 


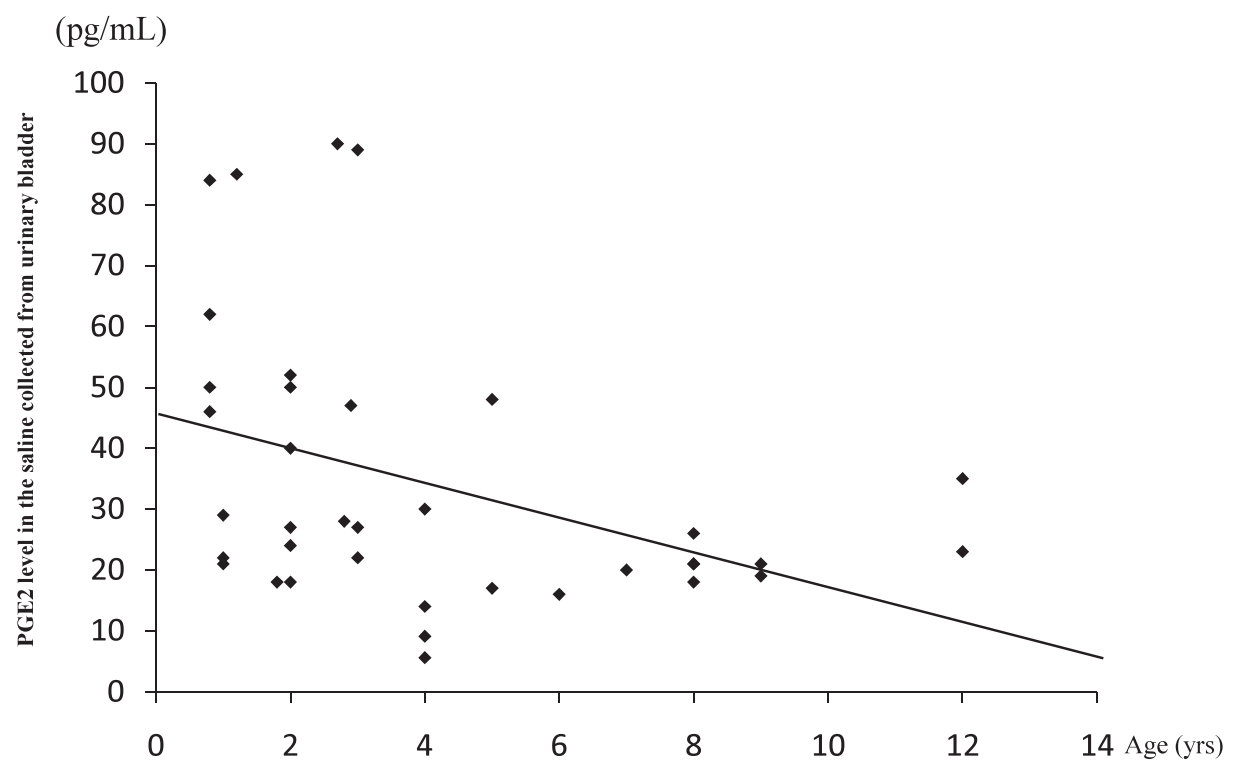

Fig. 4 Relationship between the PGE2 level in the urinary bladder and age. PGE2 in the urinary bladder showed a significant negative correlation with age $(r=-0.379, P=0.0207)$.

fluencing PGE2 production in the bladder and we discarded samples with a high value of $\mathrm{Cr}$, we believe that these results show that the increase of PGE2 in the bladder is induced by LUTO. Boys with LUTO had severe storage symptoms, such as urgency and enuresis, compared to those without LUTO. In adults, excessive PGE2 in the bladder is known to induce detrusor overactivity and cause deterioration of storage symptoms, and a similar mechanism may be present in boys with LUTO. Voiding detrusor pressure is reported to be higher in male infants than in elder children or adults, with normalization of high pressure voiding with maturation in accordance with an increase in bladder capacity $(4,14,18)$. Yeung et al. have suggested that a greater resistance to urine outflow causes high pressure voiding in infants (18). This research suggested that the PGE2 level was associated with $\mathrm{OAB}$ symptom in boys with LUTO as well as adults.

In study 2, the PGE2 level in the bladder showed a negative correlation with age, whereas IgnatowskaSwitalska et al. observed an age-dependent increase in PGE2 in the urine among healthy newborns and infants, possibly due to the maturation of enzymes for biosynthesis of PGE2 during renal growth (5). These opposite results suggest that high pressure voiding in infants may induce excessive PGE2 production in the bladder. From these results, we suggest that high pressure voiding in infants lead to stimulation of PGE2 production.
In a study of acquisition of bladder control in young children, Jansson et al. (6) found a tendency for earlier acquisition of bladder control in girls than in boys, although the difference did not reach statistical significance. In the current study, we evaluated PGE2 in boys only, but we plan to study the difference in the PGE2 concentration between boys and girls and its impact on acquisition of bladder control. From the current results, we conclude that the PGE2 level in the urinary bladder in boys with LUTO is significantly higher than in those without LUTO and has a tendency to decrease with age. Therefore, measurement of PGE2 in the bladder using our approach might serve as a biomarker for diagnosis of LUTO and acquisition of bladder control in boys. This proposal requires further examination in a study with a larger number of patients.

\section{REFERENCES}

1. Andersson KE (1993) Pharmacology of lower urinary tract smooth muscles and penile erectile tissues. Pharmacol Rev 45, 253-308.

2. Bultitude MI, Hills NH and Shuttleworth KE (1976) Clinical and experimental studies on the action of prostaglandins and their synthesis inhibitors on detrusor muscle in vivo and in vitro. Br J Urol 48, 631-637.

3. Catella F, Nowak J and Fitzgerald GA (1986) Measurement of renal and non-renal eicosanoid synthesis. Am J Med 81, 23-29.

4. Ichino M, Igawa Y, Seki S, Ishizuka O and Nishizawa O (2007) Natural history and etiology of high pressure voiding in male infants. $J$ Urol 178, 2561-2565.

5. Ignatowska-Switalska H and Januszewicz P (1980) Urinary 
prostaglandins E2 and F2 $\alpha$ in healthy newborns, infants, children, and adults. Prostaglandins Med 5, 289-296.

6. Jansson UB, Hanson M, Sillen U and Hellstrom AL (2005) Voiding pattern and acquisition of bladder control from birth to age 6 years - a longitudinal study. J Urol 174, 289-293.

7. Komhoff M, Tekesin I, Peters M, Leonhard An and Seyberth HW (2005) Perinatal management of a preterm neonate affected by hyperprostaglandin E2 syndrome (HPS). Acta Paediatr 94, 1690-1693.

8. Kuzmic AC, Brkljacic B and Ivankovic D (2001) Sonographic measurement of detrusor muscle thickness in healthy children. Pediatr Nephrol 16, 1122-1125.

9. Maggi CA, Giuliani S, Conte B, Furio M, Santicioli P, Meli P, Granqnani L and Meli A (1988) Prostanoids modulate reflex micturition by acting through capsaicin-sensitive afferents. Eur J Pharmacol 145, 105-112.

10. Nonomura K, Kanno T, Kakizaki H, Koyama T, Yamashita T and Koyanagi T (1999) Impact of congenital narrowing of the bulbar urethra (Cobb's collar) and its transurethral incision in children. Eur Urol 36, 144-148.

11. Park JM, Yang T, Arend LJ, Schnermann JB, Peters CA, Freeman MR and Briqqs JP (1999) Obstruction stimulates COX-2 expression in bladder smooth muscle cells via increased mechanical stretch. Am J Physiol 276, F129-136.

12. Schroder A, Newgreen D and Andersson KE (2004) Detrusor responses to prostaglandin E2 and bladdet outlet obstruction in wild-type and EP1 receptor knockout mice. J Urol 172, $1166-1170$.

13. Schssler B (1990) Comparison of the mode of action of prostaglandin E2 (PGE2) and sulprostone, a PGE2-derivative, on the lower urinary tract in healthy women. A urodynamic study. Urol Res 18, 349-352.

14. Sillen U (2004) Bladder function in infants. Scand J Urol Nephrol Suppl 215, 69-74.

15. Walker RD and Garin EH (1999) Urinary prostaglandin E2 in patients with vesicaoureteral reflux. Child Nephrol Urol 10, $18-21$

16. Wallis MC and Khoury AE (2006) Symptom score for lower urinary tract dysfunction in pediatric urology. Curr Urol Rep 7, 136-142.

17. Yanagisawa H, Morrissey J and Klahr S (1991) Mechanism of enhanced eicosanoid production by isolated glomeruli from rats with bilateral ureteral obstruction. Am J Physiol 261, F248-255.

18. Yeung CK, Godley ML, Ho CK, Ransley PG, Duffy PG, Chen CN and Li AK (1995) Some new insights into bladder function in infancy. $\mathrm{Br} J$ Urol 76, 235-240.

19. Yokoyama O, Yusup A, Oyama N, Aoki Y, Miwa Y and Akino H (2007) Improvement in bladder storage function by tamsulosin depends on suppression of C-fiber urethral afferent activity in rats. $J$ Urol 177, 771-775. 
